\title{
Do financial variables help predict the state of the business cycle in small open economies? Evidence from Switzerland
}

\author{
Mario Meichle • Angelo Ranaldo • Attilio Zanetti
}

Published online: 28 October 2011

(C) Swiss Society for Financial Market Research 2011

\begin{abstract}
We analyze the forecasting ability of financial variables to predict the state of the Swiss business cycle up to eight quarters ahead. Overall, our results suggest that financial variables convey leading information for the prediction of business cycles, even when applied to a small open economy. However, we clearly find that model specifications need to be extended to include variables accounting for external shocks, such as exchange rates or international commodity prices. It also appears that the forecasting contribution of individual variables changes over time. Specifically, in the last two decades, stock market liquidity has replaced the term spread as the best single predictor.
\end{abstract}

Keywords Financial market variables $\cdot$ Business cycle $\cdot$ Probit models $\cdot$ Switzerland JEL Classification E32 $\cdot$ E37 $\cdot$ E44

The opinions expressed in this paper are solely those of the authors and do not necessarily reflect the views of their affiliations.

M. Meichle

Swiss Federal Finance Administration, Bern, Switzerland

A. Ranaldo · A. Zanetti ( $₫)$

Swiss National Bank, 8022 Zurich, Switzerland

e-mail: attilio.zanetti@snb.ch

A. Ranaldo

University of Zurich, Zurich, Switzerland

A. Zanetti

University of Basel, Basel, Switzerland 


\section{Introduction}

Timely assessment of business cycle conditions is a key issue for the adoption of appropriate monetary policy decisions. As monetary impulses take time to pass through to the real economy, monetary authorities are advised to adopt a forward-looking stance. Inflationary pressures and deviations from full employment conditions, i.e., the standard elements of any central bank's loss function - are minimized if the appropriate interest rate moves are implemented ahead or in the early stages of cyclical upswings or downturns. Reliable information on upcoming directional changes of the economy can provide a significant contribution to shaping appropriate countercyclical policies.

The timing of turning points being extremely hard to predict within standard time series or structural forecast models, economists have looked for alternative instruments, specifically designed for this purpose. A popular approach is the estimation of turning point probabilities using probit models that rely on financial market information. Financial market variables are good candidates to take on the role of leading indicators for the real activity for several reasons. First, from a theoretical point of view: In liquid and well-functioning markets, financial market prices are formed on the basis of participants' rational discounting of expected future returns which, in turn, are linked to future developments in the real economy. Second, financial market data are observed, not estimated, and thus go unrevised. Third, they are readily available and at a high frequency.

In practice, when it comes to specifying the forecasting models, the question arises of precisely which financial market variables ought to be considered. Although the literature is far from conclusive in this respect, some regularities have emerged. On the one hand, the term spread frequently stands out as the best individual predictor. This result is supported by a fairly large body of empirical research and has acquired the status of conventional wisdom (Rudebush and Williams 2009). On the other hand, it often appears that further variables-such as monetary aggregates, interest rates for various maturities, risk premia, stock prices, and volatility measures-can provide useful complementary information. None of these additional variables, however, comes up in any systematic way across the various investigations.

These consolidated views have recently been challenged by Naes et al. (2011). These authors point to stock market liquidity as a new and so-far neglected dimension of financial markets that ought to be considered. They claim that stock market liquidity is superior to the term spread as a predictor.

The latter result seems to confirm the analysis of Stock and Watson (2003), who clearly pointed out that the link between financial market variables and future real economic activity is highly unstable, both across countries and over time. In light of this substantial instability, this paper deals with the question of whether existing empirical results, which are essentially based on the investigation of financial market variables' predictive power for turning points in large economies, can be confidently extended to small open economies. There are two potential specificities that need to be considered.

First, in any small open economy, financial market variables might carry information that is not relevant to the country-specific cyclical perspectives as these variables might, at least partly, be driven by fully exogenous factors. Let us take the term 
spread as an example. In a large economy, changes in this variable are exclusively determined by factors directly related to domestic business cycle conditions: monetary policy for short maturities, fiscal policy as well as expectations regarding future inflation, and business cycle conditions for longer maturities. In a small open economy, by contrast, long-term interest rates to some extent simply comove with international long-term rates. This could significantly weaken the predictive power of the term spread.

Second, there might be some otherwise little considered variables that could instead prove to be of substantial interest, specifically for small open economies. A valuable contribution could stem from variables capturing the dynamics of the international business cycle — such as raw materials prices-or from variables which would account for relevant exogenous idiosyncratic shocks (exchange rate).

In this paper, we investigate the information content of financial market variables in predicting Swiss turning points. We start with a broad basket of variables and use a stepwise probit approach to select the appropriate leading indicators for various forecast horizons. Our conclusions are as follows:

- Although the forecasting performance is far from perfect, financial market variables do provide useful information regarding future Swiss business developments.

- With respect to the race for the status of most relevant variable, our results are very clear. In the large sample (i.e., period from 1975 to 2010), the term spread is confirmed as the benchmark variable. However, if the sample is limited to the period for which stock market liquidity measures are available (i.e., after 1990), then this latter variable becomes the single most relevant variable, whereas the information provided by the term spread becomes completely irrelevant.

- Other variables can play a significant complementary role, in particular the shortterm interest rate, stock returns, the real exchange rate, monetary aggregates as well as industrial material prices. Which variables enter the model for which forecast horizon varies according to the model selection criteria.

- In line with the existing literature, we show that in and out-of-sample tests produce similar but not identical results.

The rest of the paper is organized as follows. Section 2 provides a brief overview of the existing literature. Section 3 introduces our definition of turning points. Section 4 describes the econometric approach and discusses our findings. Section 5 concludes.

\section{Benchmark literature}

There is a large and growing body of empirical literature on the predictive power of financial market variables with respect to future developments in real activity. Standard variables included in these studies are: monetary aggregates, interest rates for various maturities, term spreads, risk premia, stock prices, and volatility measures. Some results emerge consistently across various investigations. In particular, the term spread-typically computed as the difference between a ten-year government bond and an uncovered short-term interest rate-has attracted considerable attention (Estrella and Hardouvelis 1991; Estrella and Mishkin 1997, 1998; Estrella et al. 2003; Bernard and Gerlach 1998; Dotsey 1998). 
Estrella and Mishkin (1998), for example, evaluate the usefulness of a broad range of financial market variables to predict recessions and compare results with the performance of alternative models, based on more traditional macroeconomic leading indicators. For the very short run (one to three quarters), stock prices display a significant predictive power, although it does not appear to be superior to that of standard composite leading indicators. The slope of the yield curve, instead, clearly stands out as a provider of additional information. Based on pseudo out-of-sample forecasts, Estrella and Mishkin isolate it as the best single leading indicator over all forecast horizons between 2 and 8 quarters. ${ }^{1}$

Other variables such as stock returns, the volatility of stock returns, corporate bond risk premia, exchange rates or monetary aggregates find little support, at least in US data (Bernanke 1990; Stock and Watson 2003).

More recently, Wright (2006) has argued that the yield curve might carry more information regarding future turning points than what is provided solely by the 3-month over 10-year term spread. In particular, changes in the spread hide information on whether they stem from movements in the short-run interest rate, the longrun rate or a combination of the two. He shows that, in the US case, expanding the term-spread-based model with the Fed funds rate leads to better in and out-of-sample results, reflecting the fact that monetary policy impulses are taken more explicitly into account.

New findings have challenged the role of the term spread. Fornari and Mele (2009) claim that a smoothed measure of changes in stock market volatility does a better job than the term spread in predicting US turning points. Naes et al. (2011) highlight the importance of stock market liquidity. Once such measures are taken into account, the term spread turns out to be insignificant in models that predict US GDP growth.

As far as Switzerland is concerned, the only pieces of research we are aware of are Fischer (1994) and Alessandrini (2003). The former author analyzes comovements between the term spread and various measures of economic growth over the period 1966q1-1993q1. He finds fragile evidence of the term spread's predictive power. The analysis is entirely based on in-sample OLS regression results. Alessandrini investigates the 1970-2000 period. He finds that the term spread and equity returns taken together provide a satisfactory in-sample fit at horizons between 4 and 6 quarters ahead. These variables are, however, dominated by an index measuring the monetary policy stance, particularly at longer horizons. The author concludes that financial market variables derive their forecasting power from their link with monetary policy developments. Our paper differs from the works of Fischer and Alessandrini in several respects. First, we use a different - and in our view more relevant - definition of the business cycle. While they both refer to the classical cycle-in which positive GDP growth defines expansions and negative GDP growth defines recessions-we adopt the so-called growth cycle, which puts output gap changes center stage. Suppose that, starting from an initial full employment condition, a given economy grows at a positive but tiny rate over several quarters. During this period, GDP never contracts (hence, such a development does not meet the criterion of a recession in the

\footnotetext{
${ }^{1}$ For a theoretical discussion of the predictive power of the yield curve, see Estrella (2004) and Estrella et al. (2003).
} 
classical-cycle definition), but the output gap turns increasingly negative, capacity utilization falls and unemployment increases. In such an environment, the central bank is likely to react by loosening policy. Second, our sample covers the period 1975q1-2010q4. Thus, we explicitly neglect the beginning of the seventies, characterized by the convergence from a fixed to a flexible exchange rate regime. Third, we make use of a new-and more appropriate-historical series for long-term interest rates. ${ }^{2}$ Fourth, we expand the circle of potential explanatory variables to a much more comprehensive set. Several of the additional variables will prove to be useful.

\section{Financial market variables and the Swiss business cycle}

\subsection{Defining expansions and recessions}

In Switzerland, there is no official chronology of business cycles which we might refer to. We thus need to define turning points, and hence recession and expansion periods. For this purpose, we take estimates of the output gap as our benchmark variable. We define $t$ as a turning point whenever two conditions are met: (i) a change in direction occurs, i.e., a positive output gap starts decreasing after a peak or a negative output gap begins to shrink after a trough; (ii) the directional change persists for at least two quarters. ${ }^{3}$ This definition of turning points corresponds to what the literature names growth cycles: recessions are identified as periods when actual GDP growth falls short of potential growth (but does not necessarily turn negative) and expansions as periods when GDP growth exceeds potential growth. An alternative definition is provided by the classical cycle, which postulates that expansions are periods of growing GDP while recessions are periods of declining GDP. From a monetary policy standpoint, the classical-cycle definition does seem to be the most appropriate choice.

Figure 1 plots our estimates of the Swiss output gap since 1975 as a percentage deviation from the full employment condition. Estimates are based on a productionfunction approach. The methodological details of these estimates are documented in Luescher and Ruoss (1996). White-shaded areas correspond to expansion periods, while grey-shaded areas signal recessions.

Over the whole sample, the Swiss economy has experienced eleven cycles of various lengths. Expansion phases tend to last somewhat longer than recessions. The average length of expansions is 7.2 quarters, while that of recessions is 5.8 quarters. The length of expansions ranges between 2 and 14 quarters. Recessions have also

\footnotetext{
${ }^{2}$ The Swiss National Bank has released a new historical data set which extends and improves the time series on Swiss confederation bond yields. See SNB (2007) for more detailed information.

${ }^{3}$ The business cycle literature provides no clear directions regarding the minimum phase length. According to a widely accepted definition, business cycles last between 6 and 32 quarters (Stock and Watson 1998). Consequently, the minimum duration of a cyclical phase can range between 2 and 3 quarters. We consider 2 quarters to be the appropriate unit but additional tests using 3 quarters delivered similar outcomes. As a benchmark, the NBER definition of a recession reads as follows: "A recession is a significant decline in economic activity spread across the economy, lasting more than a few months ..."
} 


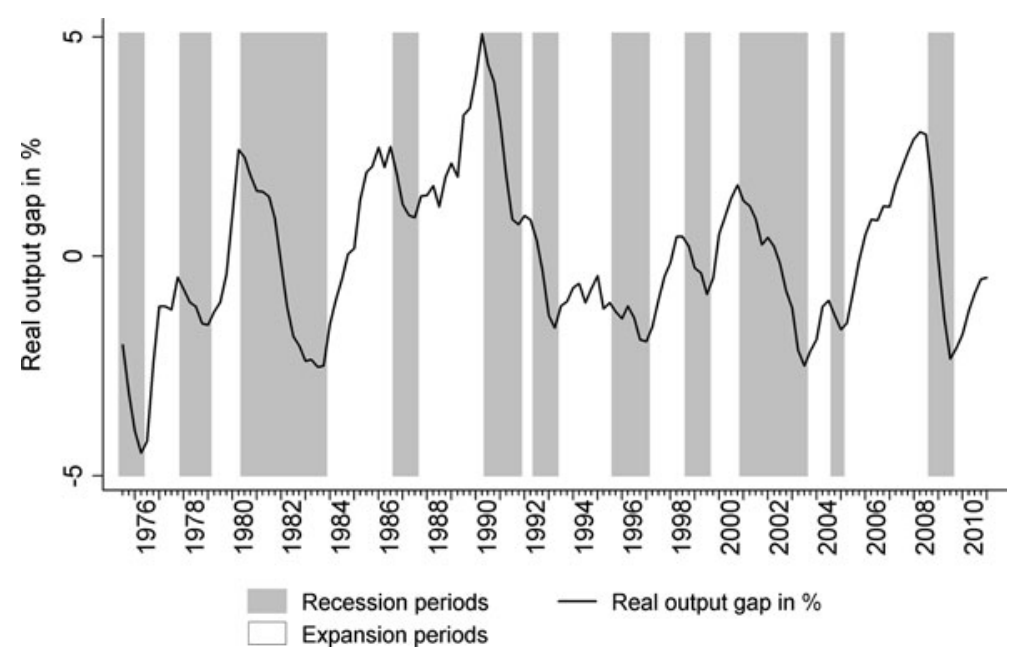

Fig. 1 Output gap and business cycle state

lasted between 2 and 14 quarters (the latter corresponds to the severe recession of the early 1980s). ${ }^{4}$

\subsection{Explanatory variables}

Table 1 provides an overview of the variables we will evaluate as potential predictors. In addition to standard financial market variables_-such as money market and capital market rates, term spreads, ${ }^{5}$ stock returns, stock market volatility, and exchange rates - we will also assess the meaning of Fornari and Mele's (2009) volatility of volatility and of Naes et al.'s (2011) measures of stock market liquidity. Other variables that we loosely place in the broad category of financial market variables are also considered: nominal and real monetary aggregates as well as commodity prices. We present results based on a total of 36 variables.., 7

Regressions are based on quarterly data. Financial market variables are obviously available at higher frequencies. Quarterly values are obtained by averaging daily or

\footnotetext{
${ }^{4}$ At first sight, it might seem that Swiss recessions are extraordinarily long in an international comparison. This is explained by the fact that we use the growth-cycle definition of cycles. If we applied the more popular classical-growth definition, we would observe an average recession length of 3.6 quarters (min: 2 quarters; max: 6 quarters).

${ }^{5}$ The influence of the new monetary policy strategy that the Swiss National Bank (SNB) adopted at the beginning of 2000 on the term structure of Swiss interest rates was recently analyzed by Gerlach-Kristen (2007).

${ }^{6}$ Our initial set of variables was even larger. It included more commodity prices (gold, silver, platinum, copper, palladium, energy, oil, heating oil), corporate bond returns, as well as risk premia measures. Having proved of no interest for our purposes, we dropped all these variables in an early stage of our analysis.

${ }^{7}$ We implemented four different unit root tests for each individual variable. We consider a variable to be unit root only if at least three out of four tests point in this direction. This criterion suggests we treat our interest rate series (int $3 m$, conflo) as unit-root variables. Both variables will therefore enter regressions in first differences (dint3m, dconf10).
} 
Table 1 Overview of variables

\begin{tabular}{ll}
\hline Variable & Description \\
\hline Interest rates & \\
conf10 & Interest rate on 10-year confederation bonds \\
int3m & 3-month interbank rate \\
tsconf10 & Term spread (conf10-int3m) \\
dconf10 & First difference of interest rate on 10-year confederation bonds \\
dint3m & First difference of 3-month interbank rate \\
dtsconf10 & First difference of term spread (conf10-int3m) \\
Stock market & \\
indexspi & Ratio of daily absolute stock return to daily trading volume, averaged across \\
securities and then across time \\
dlz
\end{tabular}

\section{Commodities general}

spcom

Log level of Standard \& Poor's commodity spot price index

dspcom

Log difference of Standard \& Poor's commodity spot price index

\section{Commodities metals}

indmet

dindmet

Log level of Standard \& Poor's industrial metals spot price index

Log difference of Standard \& Poor's industrial metals spot price index

\section{Commodities energy/oil}

spenerg

oilusd

dspenerg

doilusd

\section{Exchange rates}

loglevel

reer

dreer
Log level of Standard \& Poor's energy spot price index

Log level of oil price spot USD

Log difference of Standard \& Poor's energy spot price index

Log difference of oil price spot USD
Log level of trade-weighted real exchange rate (deflator CPI, 24 countries)

Log difference of trade-weighted real exchange rate (deflator CPI, 24 countries)

monthly observations. Compared to, for example, using end-of-quarter observations, taking quarterly averages has the advantage of smoothing the time series. In this respect, we follow a well-established procedure in the literature. 
Table 1 (Continued)

\begin{tabular}{ll}
\hline Variable & Description \\
\hline Monetary aggregates & \\
mbn & Log level of seasonally adjusted nominal monetary base \\
mbr & Log level of seasonally adjusted real monetary base (deflator CPI) \\
m1n & Log level of seasonally adjusted nominal M1 \\
m1r & Log level of seasonally adjusted real M1 (deflator CPI) \\
m2n & Log level of seasonally adjusted nominal M2 \\
m2r & Log level of seasonally adjusted real M2 (deflator CPI) \\
m3n & Log level of seasonally adjusted nominal M3 \\
m3r & Log level of seasonally adjusted real M3 (deflator CPI) \\
dmbn & Log difference of seasonally adjusted nominal monetary base \\
$d m b r$ & Log difference of seasonally adjusted real monetary base (deflator CPI) \\
$d m 1 n$ & Log difference of seasonally adjusted nominal M1 \\
dm1r & Log difference of seasonally adjusted real M1 (deflator CPI) \\
dm2n & Log difference of seasonally adjusted nominal M2 \\
dm2r & Log difference of seasonally adjusted real M2 (deflator CPI) \\
dm3n & Log difference of seasonally adjusted nominal M3 \\
dm3r & Log difference of seasonally adjusted real M3 (deflator CPI) \\
\hline
\end{tabular}

\section{Regression analysis}

The empirical approach is based on probit regressions. Referring to the results of Fig. 1, we define a binary variable BCS (Business Cycle State) which takes up the value of 0 during expansions and 1 during recessions. We then estimate various specifications of the general model

$$
\begin{gathered}
\operatorname{Prob}\left(B C S_{t+i}=1\right)=F\left(\alpha+\beta_{j} F M V_{j, t}\right)+\varepsilon_{t} \quad \text { where } \\
B C S_{t}= \begin{cases}0 & \text { if the economy is expanding } \\
1 & \text { if the economy is in recession }\end{cases}
\end{gathered}
$$

$F M V_{j, t}$ is the financial market variable $j$ adopted as explanatory variable, $i=$ $0, \ldots, 8$ are the various forecast horizons, $\alpha$ and $\beta_{j}$ are the constant and slope coefficients and $F(\cdot)$ denotes the standard normal cumulative distribution function. The goodness of fit is evaluated using the $p s e u d o R^{2}$ proposed by Estrella and Mishkin as well as the McFadden $R^{2}$. Note that regressions do not include the lagged dependent variable. As shown in Cuche-Curti et al. (2008), GDP revisions regularly lead to significant changes in the output gap estimates. In other words, real time estimates of the output gap are highly uncertain, reducing the usefulness of this variable for out-of-sample forecasts, which is our ultimate goal.

We start by operating only with variables available for the entire 1975q1-2010q4 sample. Given the large number of explanatory variables, we follow a stepwise pro- 


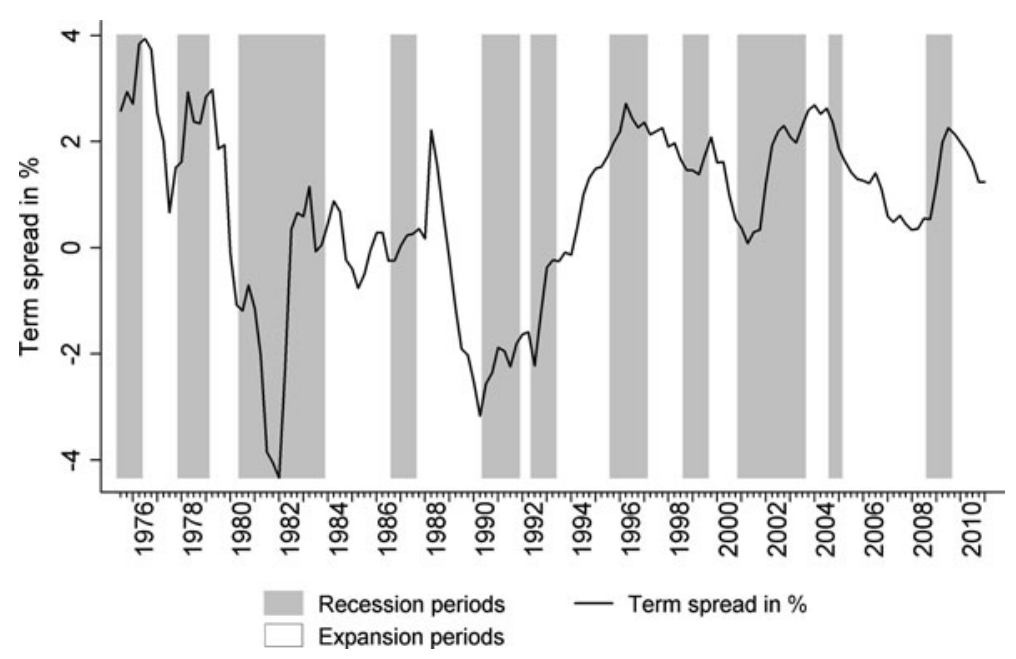

Fig. 2 Term spread and business cycle state

cedure. First, we run a set of regressions of $B C S_{t+i}$ on each explanatory variable once at a time. ${ }^{8}$ Generally speaking, adjusted $R^{2}$ turn out to be relatively low. They nevertheless allow us to identify a first important result: The term spread turns out to be the single variable which most consistently displays a significant coefficient and the highest $R$-squared across all time horizons, confirming the prior suggested by the literature. For the next steps, we thus take this univariate model as our benchmark. Figure 2 plots our term-spread variable along with the previously defined cyclical phases.

Next, we aim to identify which variables might provide further forecasting ability in addition to the term spread. We thus run a second set of regressions based on pairs of explanatory variables always holding the term spread and trying the other financial variables one by one. We focus our attention on those variables which bear a statistically significant coefficient and that guarantee an $R^{2}$ improvement as compared to the benchmark model. ${ }^{9}$ It clearly appears that no variable systematically meets our selection criteria at all time horizons. Some variables significantly complement the term spread for some specific horizons but not for others. This feature will consistently characterize our model selection throughout the paper. Taking the outcome for the various forecast horizons into account, dint $3 \mathrm{~m}$, dconf10, retspi, dreer, dm $2 n, d m 3 r$, and dindmet candidate as possible complementary variables. We select all of these variables (hereafter we will refer to this as to the selected-variable pool) and utilize them for our final round of in-sample model selection.

In order to identify the best single multivariate model for each one of our forecast horizons, $i=0, \ldots, 8$, we estimate a model which includes all of the selected

\footnotetext{
${ }^{8}$ Results are summarized in a separate Appendix available upon request.

${ }^{9}$ We base our comment on changes in the Estrella pseudo $R^{2}$ essentially. Changes in the McFadden $R^{2}$ lead to the same conclusions. Detailed results are in a separate Appendix available upon request.
} 
variables (always in addition to the term spread). Then we use an encompassing procedure to converge to the most efficient model. At each step, we eliminate the variable with the lowest $t$-statistics and we keep simplifying the model until we reach the most parsimonious specification in which all variables are significant.

The models obtained through this procedure are shown in Table 2 below. Model specifications vary depending on the forecast horizon. Models for the shorter horizons rely, besides the term spread, on dconf10, dint $3 m$, retspi, dm2n, dreer, dindmet. For horizons of 3 quarters and more, $d m 3 r$ adds information, whereas dint $3 m$ and $d m 2 n$ reemerge as valuable complements to tsconflo for 6 to 8 -quarter-ahead models. The Diff. to BM raw signals for each individual model the improvement in the Estrella $R$-squared as compared to the benchmark model.

The same procedure is then implemented for the 1990q1-2010q4 sample, while the set of variables is extended to indexspi and $d l z$, our two measures of stock market liquidity. indexspi is defined as the illiquidity ratio in Amihud (2002), i.e., the ratio between the daily absolute return for a given security and the trading volume (in units of currency) on same day. As in the original version, we compute this ratio in two steps: first, the cross-sectional mean, and then the time-series average. The former mean is based on all securities included in the Swiss Performance Index at the beginning of each quarter of year. ${ }^{10}$ A high value of the Amihud measure indicates low liquidity (or high price trading impact). The second liquidity measure- $d l z-$ refers to a liquidity measure proposed by Levine and Zervos (1998), which is based on the ratio between daily turnover of the Swiss stock market index and its market value. We compute this ratio at the end of each quarter and we take the first difference. ${ }^{11}$ The sample must be shortened because stock market liquidity variables could not be computed before 1990 .

Univariate regressions already show that the information content of the term spread is much less pronounced than in the full sample. indexspi emerges as the individual variable with the most robust link to future business cycle conditions. Results are strongly significant, in particular for forecast horizons up to three quarters ahead. Figure 3 compares the developments of indexspi with our definition of recessions and expansions.

In the following steps, we thus adopt indexspi as the benchmark variable. The pool of possible complementary variables is formed by dint3m, dconf10, dreer, dmbn, $d m 2 n, d m 3 r$, dindmet, and $d l z$. Hence, in the 1990-2010 sample, the term spread not only loses its status of the single most relevant variable, it also appears to be completely irrelevant as a complementary variable.

Table 3 describes the models identified for the various forecast horizons. Note that for models up to three-quarter-ahead horizon, the Estrella $R^{2}$ is significantly higher than for the models of Table 2.

\footnotetext{
${ }^{10} \mathrm{We}$ also compute the same ratio using the securities included in the Datastream Swiss stock index. The results are qualitatively the same.

${ }^{11}$ We considered other measures of stock market liquidity, in particular those proposed by Gibson and Mougeot (2004) and more traditional measures such as the bid-ask spread. However, these liquidity proxies convey little leading information.
} 


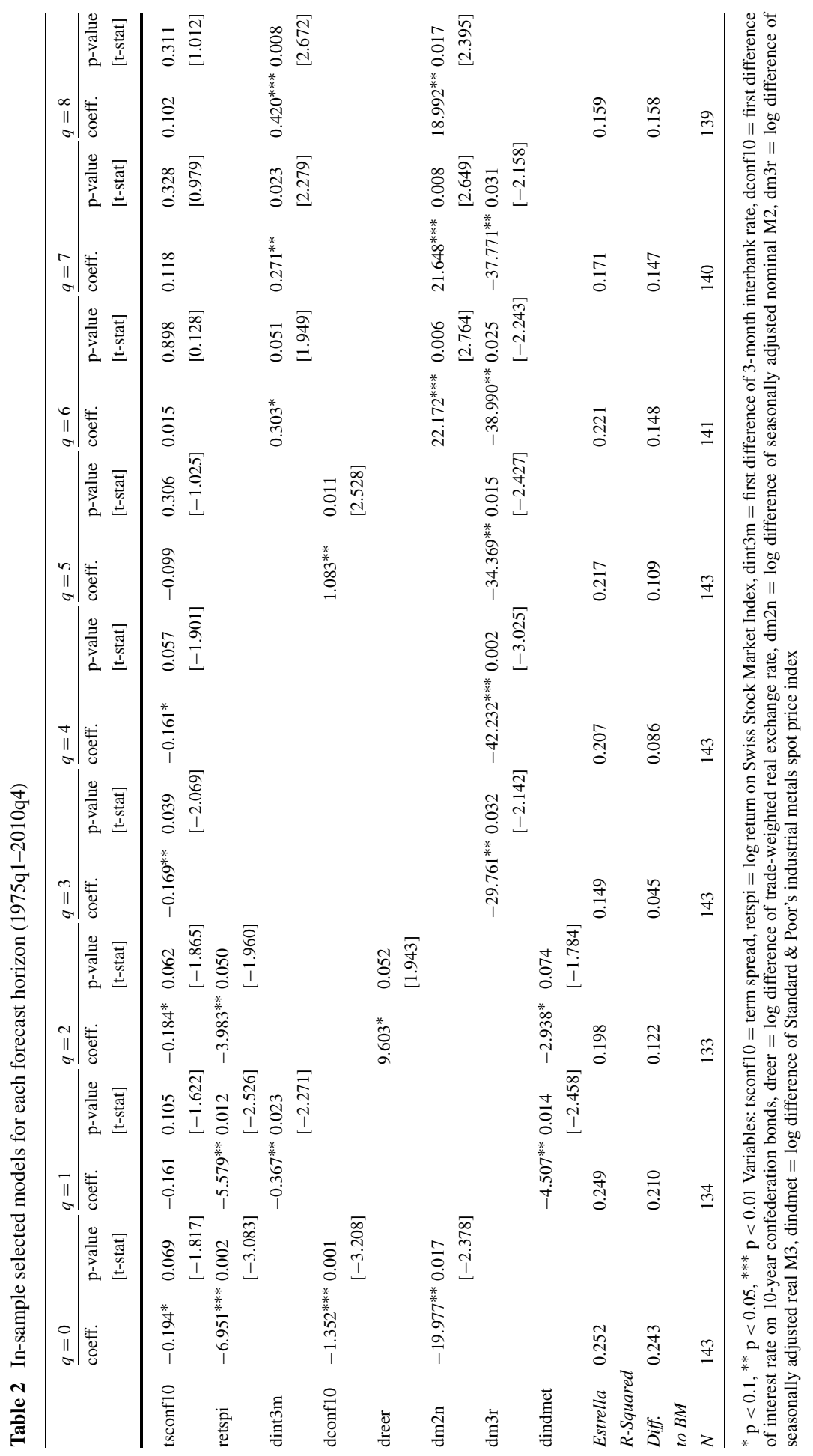




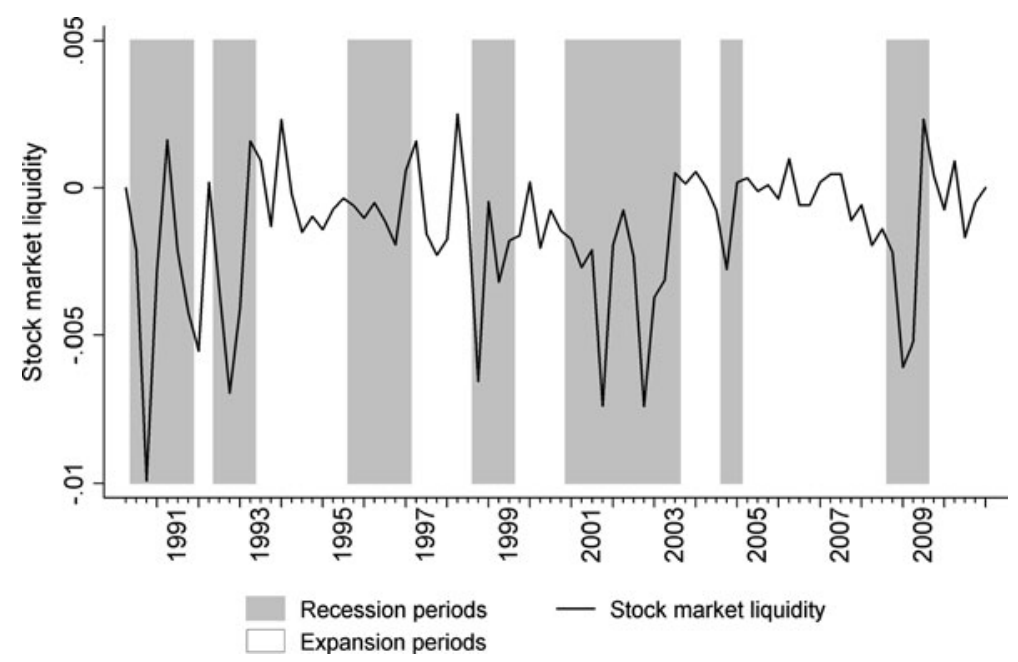

Fig. 3 Stock market liquidity and business cycle state

\section{Out-of-sample estimates}

In-sample estimates provide a first view of the link between financial market variables and cyclical turning points. However, as the literature points out, in-sample results do not necessarily lead to the most appropriate model selection from a forecasting perspective. ${ }^{12}$ Estrella and Mishkin (1998) consequently proposed to rank models according to their out-of-sample performances. ${ }^{13} \mathrm{We}$ did this by looking at the root mean squared errors resulting from pseudo out-of-sample forecasts. In light of the previous section's results, we focus exclusively on the 1990-2010 period in the remainder of this paper.

To this end, we went back to our selected-variable pool used in the context of the in-sample encompassing tests and for each combination of variables we recursively estimated models and produced zero to 8-quarter-ahead forecasts over the 2000q1$2010 \mathrm{q} 4$ period. As in the in-sample case, we take the univariate model based on indexspi as the benchmark model. The extension of the benchmark model with the variables from our pool provides 256 possible combinations. Table 4 shows for each forecast horizon the model displaying the lowest average RMSE. ${ }^{14}$

A comparison of the models in Tables 3 and 4 shows that optimal in and outof-sample specifications do diverge somewhat. The main differences as compared to Table 3 are as follows. First, some models contain variables with individually non-

\footnotetext{
${ }^{12}$ When assessing the finite-sample out-of-sample forecasts, it should be kept in mind that critical issue raised by Inouea and Kilian (2006), i.e., the risk to select over-parameterized models with positive probability.

${ }^{13}$ When assessing the finite-sample out-of-sample forecasts, the critical issue raised by Inouea and Kilian (2006), i.e., the risk to select over-parameterized models with positive probability, should be kept in mind.

${ }^{14}$ Tables showing the RMSE value for each of the 256 models as well as the detailed specification of all these models is made available in a separate Appendix.
} 


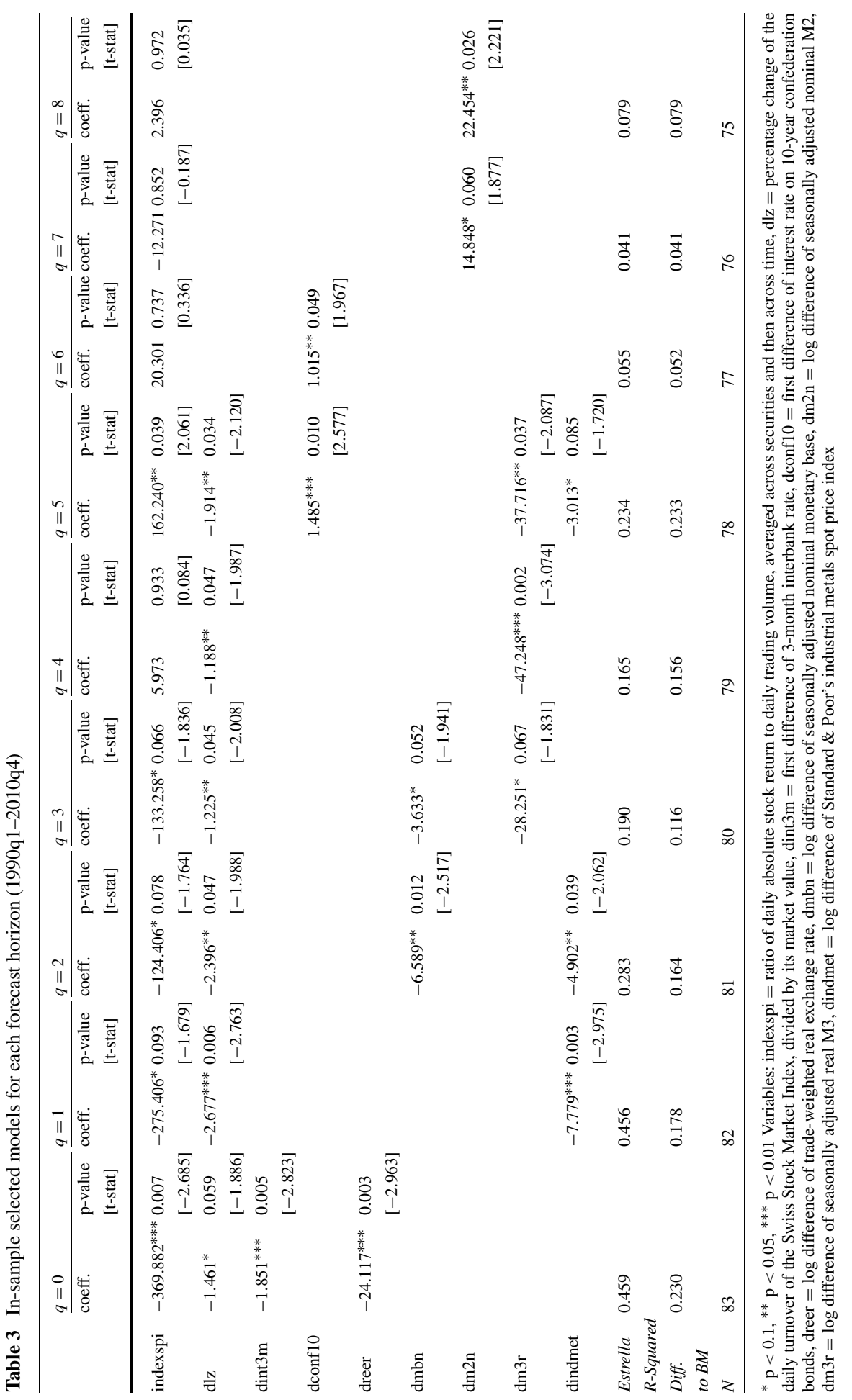




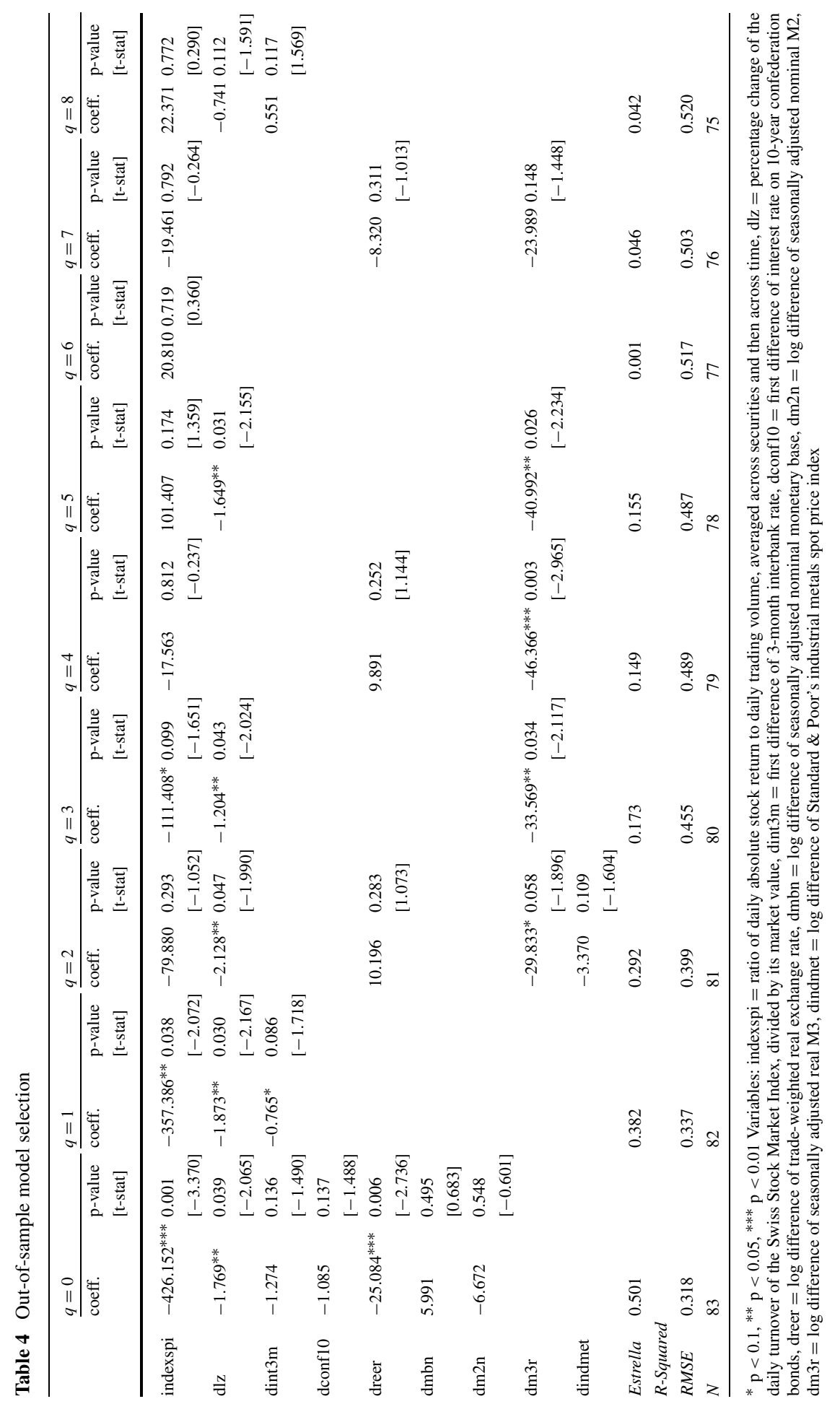




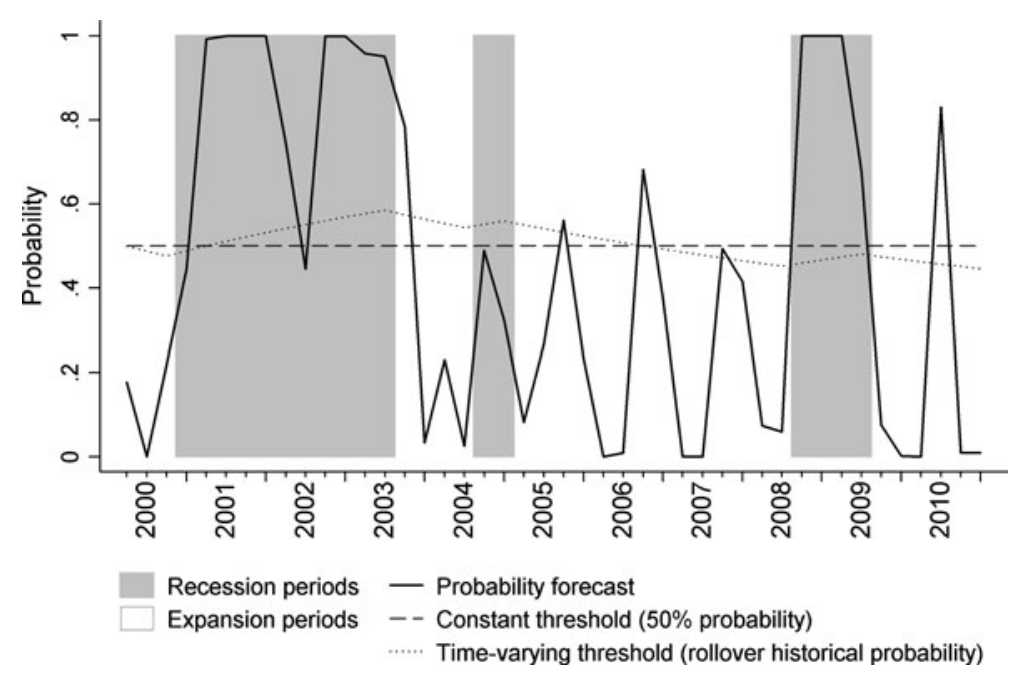

Fig. 4 Probability forecasts 0 quarters ahead

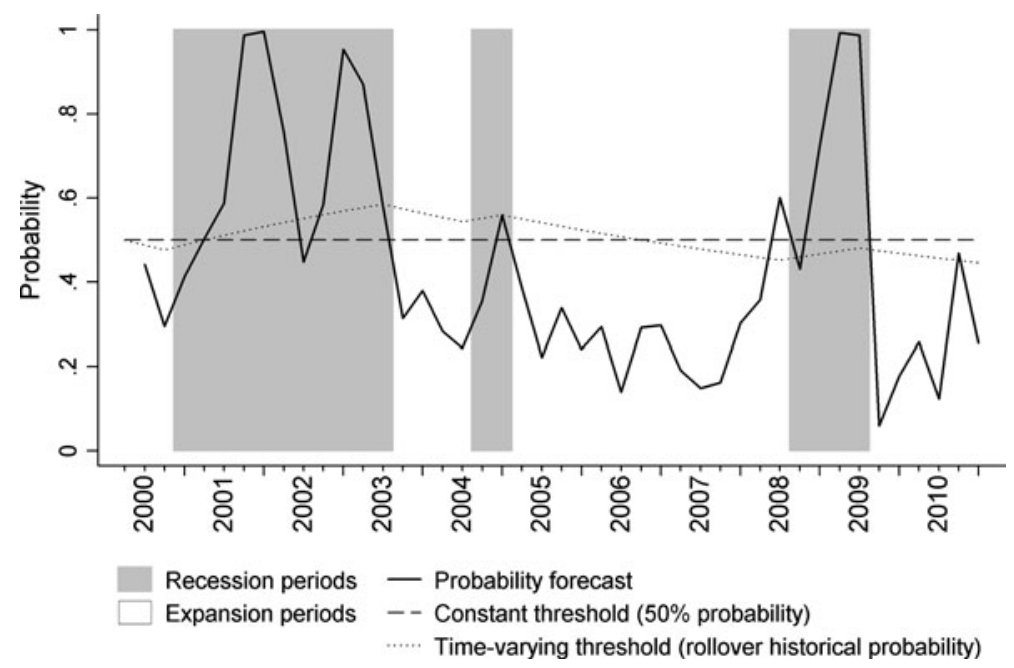

Fig. 5 Probability forecasts 1 quarter ahead

significant coefficients. Second, dint $3 m$ and dreer play a more prominent role. Third, less emphasis is put on dconf10, dmbn, $d m 2 n$, and dindmet at longer-term horizons. Also, it is worth pointing out that $d l z$ maintains a significant complementary role for various forecast horizons.

Figures 4, 5, 6, 7 provide a view of the forecasting performance of these models from zero to 3 quarters ahead. ${ }^{15}$ The gray-shaded areas mark the recession periods.

\footnotetext{
${ }^{15}$ Figures displaying the forecasting performance over the entire spectrum (i.e., from $q=0$ up to 8 quarters ahead) are available in a separate Appendix.
} 


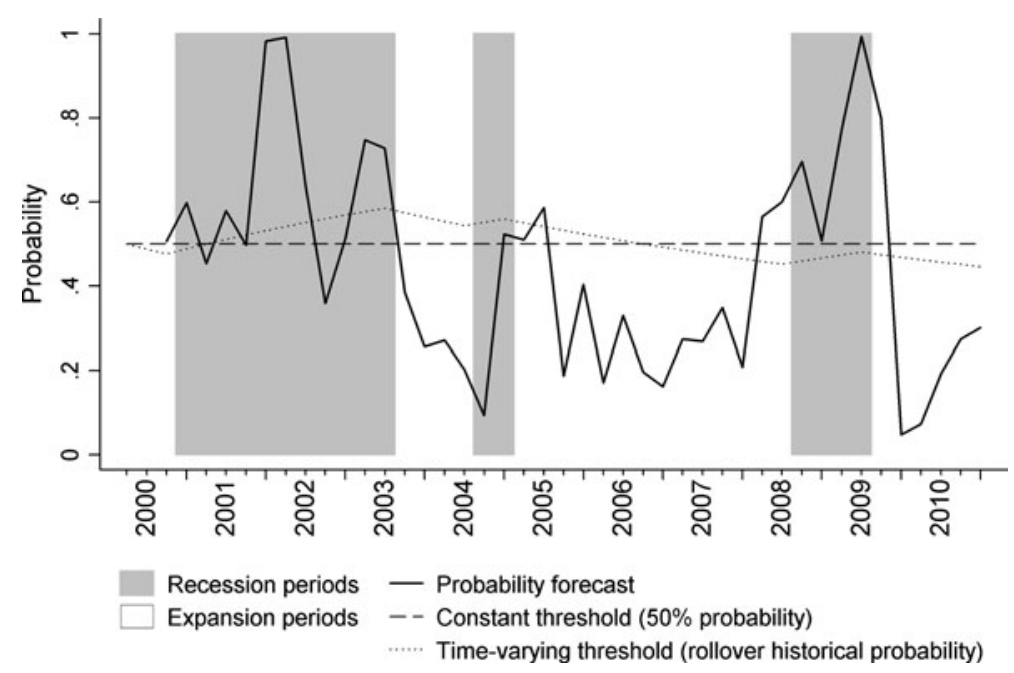

Fig. 6 Probability forecasts 2 quarters ahead

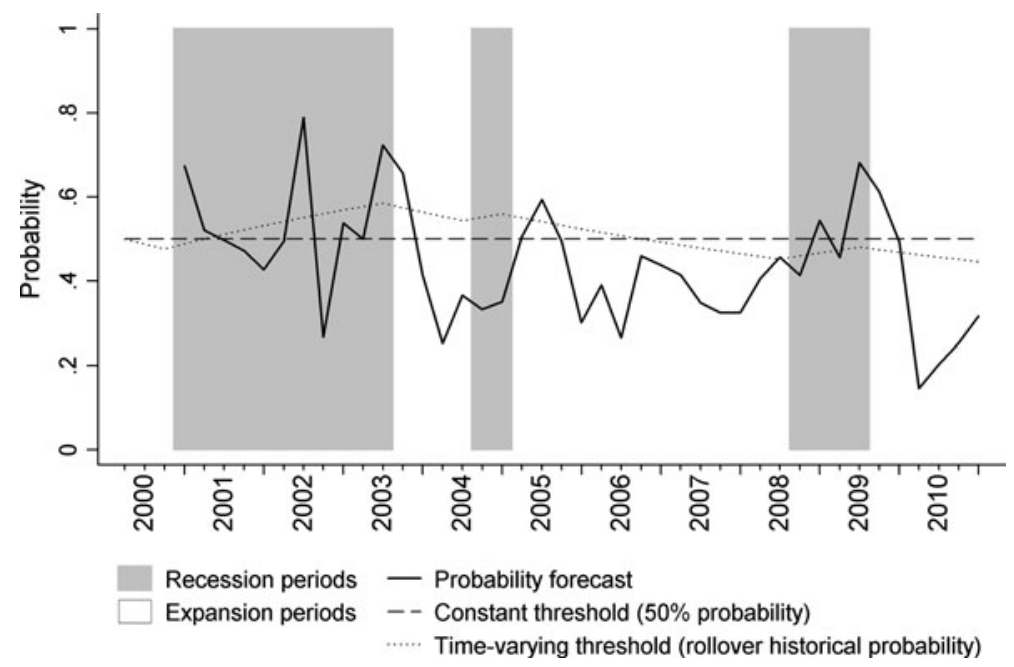

Fig. 7 Probability forecasts 3 quarters ahead

The dashed line represents a constant $50 \%$ probability threshold. The dotted line is a time-varying threshold computed as the average probability of recession over the estimation window. When the fitted value increases above these thresholds, the model signals a recession. Periods in which the fitted value lies below the thresholds are meant to correspond to expansion phases.

To conclude, our empirical findings suggest that financial variables do provide useful information to predict business cycles in the Swiss economy both in-sample and out-of-sample. However, some caveats remain. First, which variables turn out to be relevant is an issue that depends on the choice of the sample period. In particular, 
our analysis suggests that the meaning of the term spread as a valuable predictor is confirmed if we refer to the 1975-2010 sample period, but is questionable if we only refer to a more recent period of time (1990-2010). Second, the model specifications and the forecasting ability of each financial indicator tend to vary from one forecast horizon to the next. Third, the model selection differs depending on the selection criterion. More specifically, the RMSE analysis does not lead to the same choice of models as the in-sample analysis. Fourth, it clearly appears that variables such as the real exchange rate or international raw material prices can be useful in the context of such models when applied to a small open economy. Fifth, some recessions such as the one in the early 2000s, the current one and some upturns, such as the expansion that started in 2003, are better captured than others. For example, the models proposed in Table 4 failed to foresee the cyclical weakness observed between the second half of 2004 and the beginning of 2005 .

\section{Robustness checks}

The estimates we have presented are based on an expanding-window sample. As a robustness check both in and out-of-sample estimates were also made using rollingwindow samples of various sizes. The selection of relevant predictors is robust to the choice of the estimation strategy.

We replicated the in and out-of-sample analysis by using the hit ratio approach rather than the RMSE method. The main idea behind the hit ratio is to count the number of times which a given model correctly predicts the future state of the economy. We also applied the Diebold-Mariano (1995) test of relative forecast accuracy. This test is based on the mean accuracy differential between two forecasts. The results stemming from these additional tests are very consistent with those presented in our tables.

\section{Conclusion}

The early identification of turning points is crucial to optimally shape monetary policy decisions. By defining business cycle in terms of the output gap changes, three main results emerge: First, financial variables have some predictive ability to forecast turning points in the Swiss economy in and out-of-sample. Second, in the case of a small open economy, model specifications must include variables - such as the real exchange rate or international commodity prices - that can account for specific shocks. None of these variables, however, are systematically significant across models. Thus, the model specifications vary depending on the forecast horizon. Third, consistent with widespread conventional wisdom, the term spread stands out as the best individual leading indicator if we refer to the whole 1975-2010 sample. This result, however, is not confirmed in the more recent history: the term spread is clearly dominated by stock market liquidity as the main predictor in the 1990-2010 period.

Acknowledgements We thank Fabio Alessandrini, Harry Dellas, Andreas Fisher, Antonio Mele, Thomas Moser, Paul Söderlind, all the participants at the SNB brown-bag seminar, the editor, and two anonymous referees of this journal for helpful comments. We also thank Cornelius Kuth for excellent research assistance. All errors remain the authors' responsibility. 


\section{References}

Alessandrini, F.: Do financial variables provide information about the swiss business cycle? Ph.D. thesis, University of Lausanne (2003)

Amihud, Y.: Illiquidity and stock returns: cross-section and time-series effects. J. Financ. Mark. 5, 31-56 (2002)

Cuche-Curti, N., Hall, P., Zanetti, A.: Swiss GDP revisions: a monetary policy perspective. J. Bus. Cycle Meas. Anal. 4(2), 183-213 (2008)

Bernanke, B.S.: On the predictive power of interest rates and interest rate spreads. New England Economic Review 51-68 (1990)

Bernard, H., Gerlach, S.: Does the term structure predict recession? The international evidence. Int. J. Financ. Econ. 3, 195-215 (1998)

Dotsey, M.: The predictive content of the interest rate term spread for future economic growth. Federal Reserve Bank of Richmond Economic Quarterly (Summer 1998)

Diebold, F.X., Mariano, R.S.: Comparing forecast accuracy. J. Bus. Econ. Stat. 13, 253-265 (1995)

Estrella, A.: Why does the yield curve predict output and inflation? Econ. J. 115, 722-744 (2004)

Estrella, A., Hardouvelis, G.A.: The term structure as a predictor of real economic activity. J. Finance 46, 555-576 (1991)

Estrella, A., Mishkin, F.S.: The term structure of interest rates and its role in monetary policy for the European Central Bank. Eur. Econ. Rev. 41, 1375-1401 (1997)

Estrella, A., Mishkin, F.S.: Predicting US recessions: financial variables as leading indicators. Rev. Econ. Stat. 80(1), 45-61 (1998)

Estrella, A., Rodrigues, A.P., Schich, S.: How stable is the predictive power of the yield curve? Evidence from Germany and the United States. Rev. Econ. Stat. 85(3), 629-644 (2003)

Fischer, A.: Does the yield curve predict economic activity in Switzerland. In: National Differences in Interest Rate Transmission, pp. 251-264 (1994). Bank for International Settlements

Gerlach-Kristen, P.: Three aspects of the Swiss term structure: an empirical survey. J. Financ. Mark. Portfolio Manag. 21(2), 221-240 (2007)

Gibson, R., Mougeot, N.: The pricing of systematic liquidity risk: empirical evidence from the US stock market. J. Bank. Finance 28, 157-178 (2004)

Inouea, A., Kilian, L.: On the selection of forecasting models. J. Econom. 130, 273-306 (2006)

Levine, R., Zervos, S.: Stock markets, banks, and economic growth. Am. Econ. Rev. 88(3), 537-558 (1998)

Luescher, B., Ruoss, E.: Entwicklung der potentiellen Produktion in der Schweiz. Geld, Währung Konjunktur 14(1), 61-74 (1996)

Fornari, F., Mele, A.: Financial volatility and real economic activity. Unpublished manuscript (2009)

Naes, R., Skjeltorp, J.A., Odegaard, B.A.: Stock market liquidity and the business cycle. J. Finance 66(1), 139-176 (2011)

Rudebusch, G.D., Williams, J.C.: Forecasting recessions: the puzzle of the enduring power of the yield curve. J. Bus. Econ. Stat. 27(4), 492-503 (2009)

SNB: Interest rates and yields. Available on: http://www.snb.ch/en/mmr/reference/renditen_book/source (2007)

Stock, J.H., Watson, M.W.: Business cycle fluctuations in US macroeconomic time series, NBER Working Paper, N. 6528 (1998)

Stock, J.H., Watson, M.W.: Forecasting output and inflation: the role of asset prices. J. Econ. Lit. XLI, 788-829 (2003)

Wright, J.H.: The yield curve and predicting recessions. Finance and Economics Discussion Series. Federal Reserve Board (2006)

Mario Meichle is an economist at the Swiss Federal Finance Administration (FFA), working as a treasury specialist for the Federal Treasury. He obtained a Master of Science in Economics from the University of Bern, Switzerland. Before joining the FFA, he worked as a research assistant for the Swiss State Secretariat for Economic Affairs (SECO) and the Economic Analysis Unit of the Swiss National Bank (SNB).

Angelo Ranaldo is an Economic Advisor at the Swiss National Bank. He is a member of the research unit and senior management. His undergraduate studies in economics were conducted at the University Bocconi. He obtained his doctorate at the University of Fribourg (Switzerland). He was a Visiting Scholar at the New York University (Stern School of Business), a Visiting Professor at the University of Aarhus 
(Denmark), and a Visiting Senior Economist at the Federal Reserve Bank of New York. He is a lecturer at the University of Zurich and at the Gerzensee Study Centre. His papers have been published in several peer-reviewed and scholarly journals.

Attilio Zanetti is Head of the Economic Analysis Unit at the Swiss National Bank. He obtained his doctorate at the University of Fribourg (Switzerland). He is a lecturer at the University of Basel. His papers have been published in several peer-reviewed and scholarly journals. 